\title{
"Overviews" should meet the methodological standards of systematic reviews
}

\author{
Francisco M. Kovacs • Gerard Urrútia • \\ José Domingo Alarcón
}

Received: 23 July 2013/Revised: 31 August 2013/Accepted: 31 August 2013/Published online: 12 October 2013

(C) Springer-Verlag Berlin Heidelberg 2013

A recent "overview" claiming to comprehensively cover systematic reviews on surgical interventions (including thermal coagulation techniques) for low back disorders (including disc degeneration disease) [1]:

1. Overlooked reviews complying with the stated inclusion criteria [1,2].

2. Did not distinguish between "quality of reporting" and "quality of the systematic review".

3. Did not use methods which are standard in high quality systematic reviews, such as contacting the authors of the studies included to clarify aspects which appear unclear or inconsistent in their reports.

F. M. Kovacs

Departamento científico, Fundación Kovacs,

Palma de Mallorca, Spain

e-mail: kovacs@kovacs.org

F. M. Kovacs · G. Urrútia · J. D. Alarcón

Red Española de Investigadores en Dolencias de la Espalda (REIDE), Palma de Mallorca, Spain

J. D. Alarcón

e-mail: Jodomala@hotmail.com

G. Urrútia ( $\square)$

Iberoamerican Cochrane Center, Servei d'Epidemiologia Clínica

i Salut Pública, Institut d’Investigació Biomèdica Sant Pau,

Barcelona, Spain

e-mail: gurrutia@santpau.cat

G. Urrútia

CIBER Epidemiología y Salud Pública (CIBERESP)

URL: http://ciberesp.es/

J. D. Alarcón

Iberoamerican Cochrane Network, Universidad Surcolombiana,

Neiva, Colombia
4. Overlooked passages which explain aspects interpreted by the authors of the overview as contradictions between the information shown in the tables summarizing the characteristics of the trials included in a systematic review, and quotes from the corresponding original reports $[1,3]$.

High quality systematic reviews follow strict methods to enhance comprehensiveness, reduce the risk of incorrect appraisal, and increase the reliability of conclusions. We believe that it would be advisable for "overviews" to comply with the same standards. In the case of overviews including SRs on a variety of interventions for a broad spectrum of conditions, this would require more work [1]. However, we believe that it would be a worthy exercise, since it would enhance their value from academic or curricular exercises to sound and useful tools for clinicians and decision-makers.

Conflict of interest None.

\section{References}

1. Jacobs WCH, Rubinstein SM, Willems PC, Moojen WA, Pellisé F, Oner CG, Peul WC, van Tulder MW (2013) The evidence on surgical interventions for low back disorders, an overview of systematic reviews. Eur Spine J. doi:10.1007/s00586-0132823-4

2. Urrutia G, Kovacs FM, Nishishinya B, Olabe J (2007) Percutaneous thermocoagulation intradiscal techniques for discogenic low back pain. A systematic review. Spine 32(10):1146-1154

3. Kovacs FM, Urrútia G, Alarcón JD (2011) Surgery versus conservative treatment for symptomatic lumbar spinal stenosis. A systematic review of randomized controlled trials. Spine 36:E1335-E1351 